06

\title{
Photoluminescence and Photoconductivity of Lead Halide Perovskite Films Modified with Mixed Cellulose Esters ${ }^{1}$
}

\author{
(C) A.N. Aleshin ${ }^{1}$, P.P. Shirinkin ${ }^{1}$, A.K. Khripunov ${ }^{2}$, N.N. Saprykina ${ }^{2}$, I.P. Shcherbakov ${ }^{1}$, \\ I.N. Trapeznikova ${ }^{1}$, P.A. Aleshin ${ }^{1}$, V.N. Petrov ${ }^{1}$ \\ ${ }^{1}$ Ioffe Institute, \\ 194021 Saint-Petersburg, Russia \\ ${ }^{2}$ Institute of Macromolecular Compounds, \\ 199004 Saint-Petersburg, Russia \\ e-mail: aleshin@transport.ioffe.ru
}

Received January 27, 2021.

Revised January 27, 2021.

Accepted January 27, 2021.

We have investigated the photoluminescence (PL) and photoconductivity of lead halide perovskite $\left(\mathrm{CH}_{3} \mathrm{NH}_{3} \mathrm{PbBr}_{3}\right)$ films modified with different mixed cellulose esters (CEs). It was shown that the absorbance and PL spectra of $\mathrm{CH}_{3} \mathrm{NH}_{3} \mathrm{PbBr}_{3}$ : CE films contain contributions of both the $\mathrm{CH}_{3} \mathrm{NH}_{3} \mathrm{PbBr}_{3}$ and $\mathrm{CE}$ with the dominant contribution to the PL from perovskite component. The dependences of the integral PL intensities of the $\mathrm{CH}_{3} \mathrm{NH}_{3} \mathrm{PbBr}_{3}$ : $\mathrm{CE}$ films on the optical excitation power turned out to be sublinear. This indicates that exciton recombination, as well as recombination via impurity levels, occur in $\mathrm{CH}_{3} \mathrm{NH}_{3} \mathrm{PbBr}_{3}$ : $\mathrm{CE}$ films at high excitation power levels. The conductivity of $\mathrm{CH}_{3} \mathrm{NH}_{3} \mathrm{PbBr}_{3}$ : $\mathrm{CE}$ films at $300 \mathrm{~K}$ increases up to $\sim 90$ times when illuminated by a solar simulator, and this effect is environmentally stable due to the formation of hydrogen bonds between $\mathrm{CE}$ and the lead halide perovskite $\mathrm{CH}_{3} \mathrm{NH}_{3} \mathrm{PbBr}_{3}$. It is expected that appropriate selection of $\mathrm{CE}$ and optimization of $\mathrm{CE}$ inclusion will improve the optoelectronic properties and stability of composite films based on lead halide perovskite-CE composites.

Keywords: mixed cellulose esters, lead halide perovskites, photoluminescence, conductivity.

${ }^{1}$ Полный текст статьи опубликован в „Теchnical Physics“, 66 (6), 2021. 